\title{
Comparison of greenhouse and field experiments for cesium uptake in two aquatic plant species
}

\author{
J. VAcula, D. KomínKovÁ, E. PeCharová
}

Faculty of Environmental Sciences, Czech University of Life Sciences Prague, Kamýcká 129, Praha - Suchdol, 16500, Czech Republic (*correspondence: vacula@,fzp.czu.cz, kominkovad@fzp.czu.cz; pecharovae@fzp.czu.cz)

\section{Introduction}

The need for identifying aquatic plant species capable of accumulation cesium, either for phytoremediation purposes or a better understanding of its movement in aquatic habitats, is still relevant [1]. Therefore, two aquatic species Ceratophyllum demersum (CD) and Potamogeton pectinatus (PP) were tested in greenhouse (G) and field (F) experiments.

\section{Methodology}

The $2 \mathrm{~L}$ cylindrical glass flasks were divided into 4 groups with concentrations of $0,0.133,0.267,0.533 \mathrm{mM}$, contaminated with $99.99 \% \mathrm{CsCl}$. Each group had 10 repetitions. Preparation and processing of the experiment was performed according to Rinaldi et al. (2017) [2].

\begin{tabular}{|c|cccc|}
\hline Concentration & \multicolumn{4}{|c|}{ Experiment type } \\
{$[\mathrm{mM}]$} & CDF & PPF & CDG & PPG \\
\hline 0.133 & $10.82 \%$ & $34.71 \%$ & $10.08 \%$ & $11.09 \%$ \\
\hline 0.267 & $10.90 \%$ & $19.83 \%$ & $11.19 \%$ & $10.01 \%$ \\
\hline 0.533 & $11.80 \%$ & $16.64 \%$ & $8.06 \%$ & $9.58 \%$ \\
\hline
\end{tabular}

Table 1: Mean removal rates of individual experiments at different external $\mathrm{CsCl}$ concentrations.

\section{Results and Discussion}

Significantly higher accumulation $(\mathrm{p}<0.005)$ of $\mathrm{Cs}^{+}$was found in the PPF experiment compared to CDF, CDG and PPG. All other types of experiments tested were not significant differences. Removal rates for all types of experiments and concentrations are shown in Table 1.

$\mathrm{Cs}^{+}$values accumulated by $\mathrm{CDF}, \mathrm{CDG}$ and PPG are lower than those published by Rinadli et al. (2017), but PPF values are comparable with them [2].

[1] Burger \& Lichtscheidl (2018) Science of the Total Environment 618, 1459-1485. [2] Rinaldi et al. (2017) Ecotoxicology and environmental safety 139, 301-307. 